\title{
Experimental Investigation Of Polymeric Compound Cross Section Springs
}

\author{
Mayas Al-Mahasne and Tareq A. Abu Shreehah \\ Department of Mechanical Engineering, Tafila Technical University \\ P.O. Box: 52, Tafila (66110), Jordan
}

\begin{abstract}
This paper presents an experimental investigation of the characteristic of the compound cross section springs on models made from polymeric materials (organic glass). Two constructive variants of the compound spring sections were specified with the help of criteria of similarity. The criterion of similarity of natural and model springs was determined by the simulation method at particular spring deflection. The problem of simulation was brought to accurate determination of the magnitudes that characterize the physical and mechanical properties of materials for natural and model springs. It was experimentally proved that the use of the proposed new type of springs significantly increases the spring stiffness.
\end{abstract}

Key words: Coil, spring, organic glass, criteria of similarity, power characteristics

\section{INTRODUCTION}

The springs area very common and important elements in many machine and vehicles. These bodies can exhibit flexibility to the degree the designer seeks. The springs allow controlled application of force or torque; the storing and release of energy can be another purpose $^{[1]}$.

In general, springs may be classified as wire, flat, or special-shaped springs and there are variations within these divisions.

Because of machinery's value to designers, springs have been intensively studied, moreover, they are massproduced and ingenious configurations have been found for a variety of desired applications.

At the last decades, Wahl ${ }^{[2]}$ analyzed the propagation of extensional waves along the axis of a helical spring.

Jiant et $a l^{[3,4]}$ obtained non-linear equations of motion and form them linearized equations for the vibration of a spring. They studied the coupling between axial and torsional motion. Yildirim ${ }^{[5]}$ concentrated on determining the natural frequencies for arbitrarily shaped springs. Paper ${ }^{[6]}$ presented an efficient method for calculating the dynamic stiffness of a helical coil spring.

Das et $a l^{[7]}$ investigated the premature failure of suspension coil spring of a passenger car which failed within few months after being put into service.

A new type rectangular suspension helical spring for rally cars was contrived by the authors of reference ${ }^{[7]}$. It was found that the control stability can be kept well while absorbing impact from the road.

This paper presents a new type of helical spring that leads to significant increase in spring stiffness. The proposed model was simulated and experimentally investigated.

Simulation, including of model construction, studying its properties under a given conditions and transfer the obtained informations to the investigated object, permits to accelerate the solutions of the optimistic and economic-technical problems for selecting constructions and experimental results processing.

Procedures of model experiments: At present, under investigation of complex constructions that work on the range of elastic deformations, the models made from polymeric materials are wider used. The advantages of the indicated method at investigation are ${ }^{[8]}$ : the possibility of realization of models for particularly significant constructions (including compound with accurate reproduced forms, power loads, junction and rigidity conditions); small modulus of the material elasticity that permits to obtain deformations in the model (under small loads) which are sufficient for its measurement with the help of tensor transmitter; the simplicity of models realization and ease of insertion changes for comparing alternate versions of the constructions; non-essential differences in Poisson's ratio: for steel -0.28 and for model loaded at room temperature -0.35 .

In spite of similarity of methods used in different domains, the simulation didn't become independent scientific discipline and needs the application of common methods in union with the theoretical bases of the investigated phenomena that permit to determine the permissible utilization limits of the $\operatorname{method}^{[8]}$. It is known from the simulation theory that the conditions, which should be fulfilled in trials with models, are

Corresponding Author: $\quad$ Mayas Al-Mahasne, Department of Mechanical Engineering, Tafila Technical University, P.O. Box: 52, Tafila (66110), Jordan, Tel: +962-777745485, Fax: +962-3-2250033 
based on theory of dimensionality and similarity that have the following principal aspects:

1. The similar phenomena have an individual criterion of similarity

2. The relationships in model experiment do not lie between individual quantities that characterize the phenomenon, but between complex quantities which represent themselves as a criteria of similarity.

3. The similar phenomena for which the conditions of synonymicity are similar.

Hence, the simulation theory decides at which requirements the model should be responsible so that the processes occur in the model which were similar to processes that run in the natural (true) construction.

Taking into account the stated above, we find out the basic criteria equations during investigation of springs on models made from polymeric materials.

The deflection of the cylindrical spiral spring with circular cross section of its turns can be sufficiently fully described by the following equation ${ }^{[1,9]}$ :

$\mathrm{y}=\frac{8 \mathrm{FD}^{3} \mathrm{~N}_{\mathrm{a}}}{\mathrm{Gd}^{4}}$

Where $y$-is the deflection

$F$ - is the load

$D$ - is the mean diameter of the spring

$\mathrm{Na}$ - is the number of active turns

$G$ - is the shear modulus of the spring material

$d$ - is the diameter of the spring wire

Two equations differ only by its indices can be written for the natural spring and its model as follows:

$$
\begin{aligned}
& \mathrm{y}_{\mathrm{N}}=\frac{8 \mathrm{~F}_{\mathrm{N}} \mathrm{D}_{\mathrm{N}}^{3} \mathrm{~N}_{\mathrm{N}}}{\mathrm{G}_{\mathrm{N}} \mathrm{d}_{\mathrm{N}}^{4}} \\
& \mathrm{y}_{\mathrm{M}}=\frac{8 \mathrm{~F}_{\mathrm{M}} \mathrm{D}_{\mathrm{M}}^{3} \mathrm{~N}_{\mathrm{M}}}{\mathrm{G}_{\mathrm{M}} \mathrm{d}_{\mathrm{M}}^{4}}
\end{aligned}
$$

Further, we lead-in the following scale transformations:

$\frac{\mathrm{F}_{\mathrm{N}}}{\mathrm{F}_{\mathrm{M}}}=\mathrm{F}_{0} ; \frac{\mathrm{G}_{\mathrm{N}}}{\mathrm{G}_{\mathrm{M}}}=\mathrm{e}_{0} ; \frac{\mathrm{D}_{\mathrm{N}}}{\mathrm{D}_{\mathrm{M}}}=\frac{\mathrm{d}_{\mathrm{N}}}{\mathrm{d}_{\mathrm{M}}}=\mathrm{n}$

where

$F_{0}, e_{0}-$ are the constants of similarity of load and modulus of elasticity, respectively.

$n$ - is the constant of geometrical similarity or scale of simulation.

On the basis of the first theorem of similarity we obtain the condition for similarity of natures and models:

$\frac{\mathrm{y}_{\mathrm{N}}}{\mathrm{y}_{\mathrm{M}}}=\mathrm{n}$

By dividing Eq. (2) to Eq. (3) and placing Eqs. (4)(5), we obtain the first criterion of similarity:

$\mathrm{F}_{0}=\mathrm{e}_{0} \mathrm{n}^{2}$

It is well known that the spring stiffness is determined by the following relationship:

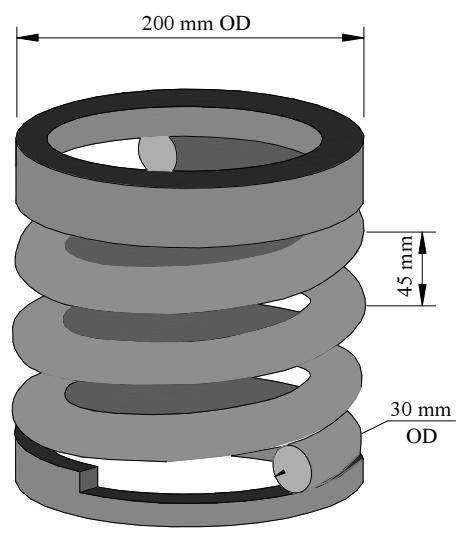

Fig. 1: The natural plain cylindrical spiral spring

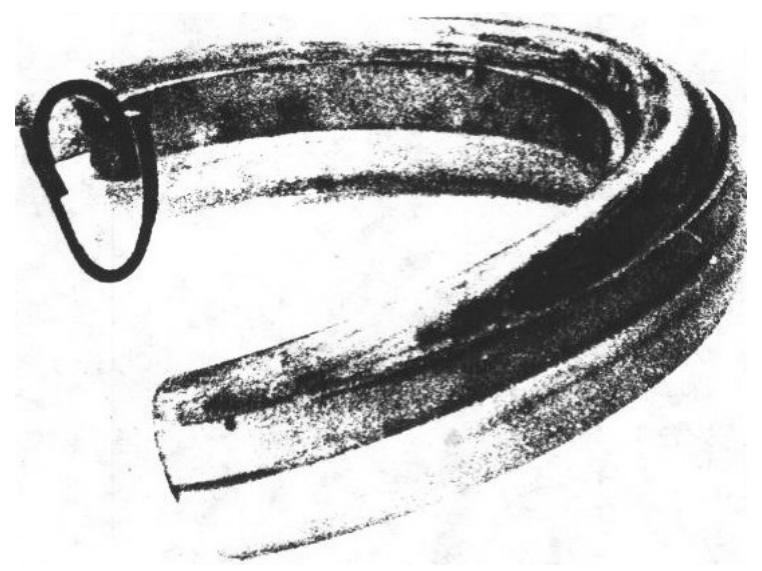

Fig. 2: Photographic illustration of turn of model spring with compound section

$\mathrm{k}=\frac{\mathrm{F}}{\mathrm{y}}$

Leading-in the corresponding scale transformations and taking into account Eqs. (4) and (6), we obtain the criterion of similarity for the stiffness:

$\mathrm{k}_{0}=\mathrm{e}_{0} \mathrm{n}$

The magnitude of the internal relative coefficient of friction in the construction of the compound spring equals:

$\varphi_{\mathrm{fr}}=\frac{\mathrm{F}_{\mathrm{fr}}}{\mathrm{F}_{\mathrm{y}}} ; \mathrm{F}_{\mathrm{fr}}=\mu \mathrm{k}_{\mathrm{t}} \Delta \mathrm{y} ;$

$\mathrm{F}_{\mathrm{y}}=\mathrm{k}_{\mathrm{s}} \Delta \mathrm{y}=\left(\mathrm{k}_{\mathrm{t}}+\mathrm{k}_{\mathrm{c}}\right) \Delta \mathrm{y} ; \varphi_{\mathrm{fr}}=\frac{\mu \mathrm{k}_{\mathrm{t}}}{\mathrm{k}_{\mathrm{t}}+\mathrm{k}_{\mathrm{c}}}$

where

$\mathrm{F}_{\mathrm{fr}}$ - is the friction force of the compound spring

$F_{y}$ - is the elastic force of the compound spring

$\mu$ - is the coefficient of friction between the surfaces of chute and insert

$k_{t^{-}}$is the stiffness of tubular element in compound spring

$\Delta y^{-}$is the maximum deflection of the spring 
Table 1: Determination of similarity constant

\begin{tabular}{|c|c|c|c|c|}
\hline $\begin{array}{l}\text { Power or force } \\
\text { parameters }\end{array}$ & Natural spring, $N^{\prime} a=3.5$ & $\begin{array}{l}\text { Natural spring } \\
N^{\prime \prime} a=1.5\end{array}$ & $\begin{array}{l}\text { Model-copy of natural spring, } \\
N a=1.4\end{array}$ & Criteria of similarity \\
\hline $\mathrm{F}, \mathrm{kN}$ & 10 & $F^{\prime \prime}=F^{\prime} \frac{N_{a}^{\prime}}{N_{a}^{\prime \prime}}=23$ & 0.487 & $F_{0}=51.3$ \\
\hline$y, \mathrm{~mm}$ & 25 & 25 & 25 & $n=1$ \\
\hline$k, \mathrm{~N} / \mathrm{mm}$ & 400 & 1000 & 19.48 & $e_{0}=51.3$ \\
\hline$\varphi_{f r}$ & - & - & - & $\varphi_{0}=0.394$ \\
\hline
\end{tabular}

Note: the criterion of similarity $\varphi_{0}$ was determined at model investigation of leaf spring

Table 2: The geometrical parameters of the model and natural springs

\begin{tabular}{|c|c|c|c|c|c|c|c|c|}
\hline \multirow{2}{*}{$\begin{array}{l}\text { Variant of } \\
\text { construction }\end{array}$} & \multirow[t]{2}{*}{ Spring } & \multirow{2}{*}{$\begin{array}{l}\text { No of } \\
\text { active } \\
\text { turns } \\
\mathrm{Na}\end{array}$} & \multirow{2}{*}{$\begin{array}{l}\text { Mean } \\
\text { diameter of } \\
\text { spring, } \\
\text { Do }(\mathrm{mm})\end{array}$} & \multicolumn{4}{|c|}{ Dimensions of turn section, $\mathrm{mm}$} & \multirow[b]{2}{*}{$\begin{array}{l}\text { Spring } \\
\text { material }\end{array}$} \\
\hline & & & & $\begin{array}{l}\text { Diameter } \\
\text { of solid } \\
\text { wire, d }\end{array}$ & $\begin{array}{l}\text { Wall } \\
\text { thickness }\end{array}$ & $\begin{array}{l}\text { Internal } \\
\text { radius of } \\
\text { chute }\end{array}$ & $\begin{array}{l}\text { Restrictive } \\
\text { insertion of } \\
\text { section } \\
\text { deformation }\end{array}$ & \\
\hline \multirow[t]{3}{*}{1} & 2 & 3 & 4 & 5 & 6 & 7 & 8 & 9 \\
\hline & Natural & 3.5 & 170 & 30 & - & - & - & Spring steel \\
\hline & Copy-model & 1.5 & 170 & 30 & - & - & - & organic glass \\
\hline I & compound & 1.5 & 170 & - & 4 & $14 / 22$ & $14 \times 3$ & -"- \\
\hline II & 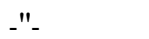 & 1.5 & 170 & - & 6 & 20 & $20 \times 16$ & _"- \\
\hline
\end{tabular}

$k_{S^{-}}$is the stiffness of compound cylindrical spring

$k_{c^{-}}$is the stiffness of the insert.

Leading-in the constant of similarity $\mu_{0}=\frac{\mu_{\mathrm{N}}}{\mu_{\mathrm{M}}}$, we obtain from Eq. (9):

$\varphi_{0}=\mu_{0}$

As seen from the system of criteria Eqs. (6), (8) and (10), the problem of simulation is brought to accurate determination of the values that characterize the physico-mechanical properties of materials for natural and model springs.

Manufacturing of models and determination of criteria of similarity: The material used for manufacturing the copy-model and compound springs was organic glass with sheet thickness ranged from 4 to $6 \mathrm{~mm}$ and has the modulus of elasticity equals $E=$ $2 \div 5 \times 10^{3} \mathrm{MPa}$.

For determination the constants of similarity, the follows were studied:

* Natural plain cylindrical spiral spring (Fig. 1)

* Copy-model of the natural cylindrical spring for which the geometrical parameters are stated in Table 1.

The experimental values of the power parameters for both natural and model springs are stated in Table 1 . The criterions of similarity determined by the simulation method at $25 \mathrm{~mm}$ deflection are also presented.

Once the constants of similarity were defined, the different constructive variants of the compound spring sections were specified. The parameters of those springs are presented in Table 2.

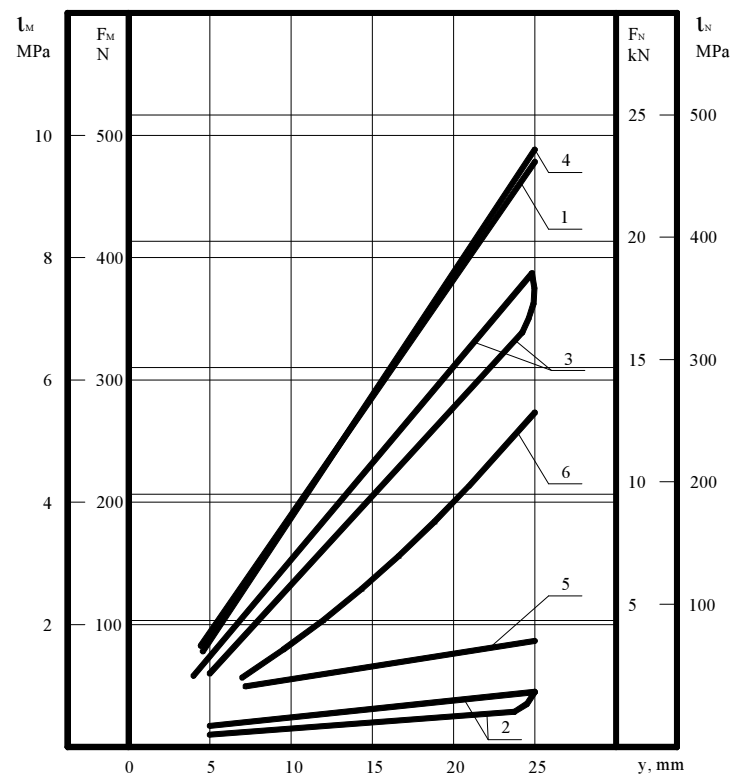

Fig. 3: Combined characteristics of models and natural type of springs: $y=f(\mathrm{~F})$ : 1 - for natural spring (model), 2- for compound spring of variant $I, 3$ - for compound spring of variant $I I$, $\tau=f(\mathrm{y})$ : 4- for natural spring (model), 5- for compound spring of variant $I, 6$ - for compound spring of variant $I I$

The development of spring construction was carried out in the direction of improving its damping capacity. In this connection, two variants of compound springs (Fig. 2) with different wall thickness were developed. In those springs, a part of its turns are enveloped by slitted ring for which the contact with the 
spiral spring is guaranteed by a dish-type springs. By means of inclined slit in the ring, in which a finger contained in, two degrees of freedom with respect to the spring-ring movement are ensured and this increases the damping efficiency.

The model investigation of elastically dissipative and strength properties of the complex (compound) sectional springs. Analysis of experimental results: Determination the experimental power characteristics of the models was carried out on special supports of cylindrical shape with screw type flange (projection) that serve as support for the end section of the model turns. For defining the stressed state on the model surface a resistance strain gauge with the output recorded on an oscilloscope was used. The measurement of the stress was carried simultaneously with the power characteristics of the model.

From the compatibility of the model power characteristics and natural spiral springs presented in Fig. 3, the followings are obvious: the stiffness of the complex sectional spring (variant I) made without damping element at the ratio $\frac{\mathrm{J}_{\mathrm{s}}}{\mathrm{J}_{\mathrm{t}}}=0.1$ (where $\mathrm{J}_{\mathrm{s}}, \mathrm{J}_{\mathrm{t}}$ are the moments of inertia for the cross sectional areas of compound and tubular springs, respectively), constituted $10 \%$ of the stiffness of the cylindrical spring with circular section of the wire at the same value of $\mathrm{D}_{0}$. An increase in the ratio $\frac{\mathrm{J}_{\mathrm{s}}}{\mathrm{J}_{\mathrm{t}}}$ up to 2 (variant II) causes an increase in spring stiffness up to $75 \%$ by comparing it with the traditional type spring.

Furthermore, the magnitude of the relative internal friction $\left(\varphi_{\mathrm{fr}}\right)$ in the investigated constructions was also studied. The coefficient ( $\varphi_{\mathrm{fr}}$ ) was equaled to 0.049 and 0.041 in variants $I$ and $I I$ respectively.

According to the recommendations stated in $^{[10]}$, for ensuring an effective damping of locomotive underframe vibration, it is necessary that the value of the relative friction in the suspension system lies in the range of $\left(\varphi_{\mathrm{fr}}=0.03\right.$ to 0.08$)$. This condition strongly satisfied in constructions of variants I and II. In those constructions the value of $\varphi_{\mathrm{fr}}$, without the effect of rubber elements activity, lies in the mentioned interval. Thus, the arrangement of these constructions in the suspension systems of transport facilities permits to refuse the use of special extinguishing means.

\section{CONCLUSION}

Characteristics of the present study exist in the following structure:

* The simulation method successfully accelerates the solutions of the optimistic and economic-technical problems for selecting constructions and experimental results processing.

* Polymeric materials have good characteristics and can be successfully used for springs manufacturing.

* At the same values of $D_{0}$, it is possible to use different variants for constructing compound springs.

* The proposed constructions of compound springs made from organic glass significantly increase the stiffness of the spring and ensure an effective damping of locomotive underframe vibration.

\section{REFERENCES}

1. Shigley, J.E., 2004. Mechanical Engineering Design. 7th Edn. New York: McGraw Hill.

2. Wahl, A.M., 1963. Mechanical Springs. 2nd Edn. New York: McGraw Hill.

3. Jiang, W., W. Jones, K. Wu and T. Wang, 1989. Non-linear, static and dynamic analyses of helical springs. The $30^{\text {th }}$ AIAA/ASME/ASCE/AHS/ASC Structures, Structural Dynamics and Materials Conf., Mobile, AL, pp: 386-395.

4. Jiang, W., W.K. Jones, T.L. Wang and K.H. Wu, 1991. Free vibration of helical springs. Trans. ASME, 58: 222-228.

5. Yildirim, V. and N. Ince, 1997. Natural frequencies of helical springs of arbitrary shape. J. Sound and Vibration, 204: 311-329.

6. Lee, J. and D.J. Thompson, 2001. Dynamic stiffness formulation, free vibration and wave motion of helical springs. J. Sound and Vibration, 239: 297320.

7. Watanabe, K., M. Tamura, K. Yamaya and T. Kunoh, 2001. Development of new-type suspension spring for rally cars. J. Material Process. Technol., 111: 132-134.

8. Glyshenko, A.D., G.A. Khromova and M. AlMahasne, 1996. Simulation of dynamic loading in multilayer elastic elements. J. Problems in Mechanics, 6: 161-165.

9. www.tech.plymouth.ac.uk/sme/desnotes/ Springs1. pdf

10. Al Mahasne, M., 1997. Development of calculation method for strength of leaf springs of transport means taking into account the wave dynamic. Ph.D. Thesis, Institute of Mechanics and Seismic Stability of Structures, Tashkent, Russia. 